\title{
Piropos and Friendships: Gender and Culture Clash in Study Abroad
}

\section{Susan B. Twombly}

\author{
Introduction
}

ST U D Y A B R O A D is receiving renewed attention as colleges and universities seek ways to improve language skills, enhance crosscultural understanding, and internationalize the curriculum (Carlson et al., 1990; Pickert, 1992). The National Task Force report on undergraduate education recommended that, by the year 2000, onetenth of North American college and university undergraduates should have a significant educational experience abroad before graduating (Burn and Smuckler, 1990). In support of this goal, the U.S. Congress passed the National Security Education Act of 1991, which seeks to facilitate study abroad and to increase support in related areas such as language instruction. The ultimate goal of these initiatives is to increase international literacy among U.S. citizens and thus provide means of developing skills necessary to compete in an increasingly interdependent, multicultural world.

Despite research that stresses the positive outcomes of study abroad in achieving these lofty goals (Carlson et al., 1990), the experience of study abroad may not be so smooth for a major group of participantswomen. JoAnn deA. Wallace, director of Antioch Education Abroad at Antioch College, cautions that study abroad can be a chilly experience for "today's young women-who have been raised with a heightened awareness of sexism, oppression, and harassment" (1993, p. 5). She goes on to say that "coping with different social values, traditional sex roles, and stereotypes of American women can turn a cross-cultural adventure into a nightmare" (p. 5). A colleague and I certainly did not anticipate any nightmarish stories as we embarked on a study of how study abroad students learned about their new culture. We had been in Costa Rica for five months, and to us Costa Rica had seemed relatively progressive with respect to women's issues. We quickly learned, 
however, that women students encounter unique obstacles in the study abroad experience.

In particular, the practice of piropoing (catcalling) and difficulty making women friends in the host culture posed problems for the North American women we met during our investigation. The results of our interviews suggest that for many of the students we interviewed and observed, at least the first four months of the sojourn in the foreign country were not an immersion experience, but an alienating experience in which gender played a major role. To compound the situation, those responsible for study abroad were not fully aware of the seriousness of this "gender dynamic" for female students.

In this article I argue that educators must ask not only how gender (and race/ethnicity) affects the study abroad experience, including attitudes toward the host country, but what study abroad programs can do to turn potentially negative experiences for women students into critical learning experiences. It is neither possible nor necessarily desirable to change the host country; however, we can help young women to understand how gender roles are constructed in other cultures and better prepare them to confront the differences.

The results of this study raise many questions about the experiences of women studying abroad and how these experiences affect both adjustment to the culture and learning outcomes. The issue assumes added importance because women comprise the majority of students studying abroad in Costa Rica, and because the majority of students spend only six months in Costa Rica, shorter than the average time necessary to work through culture shock. It appears that little, if any, research has directly addressed the question of gender within the study abroad experience. Because the majority of students who participate in study abroad are women (Carlson et al., 1990), this oversight seems particularly disturbing. While attention to the role of gender in understanding the process and impact of study abroad is important in all countries, it is particularly important in Latin American countries where conceptions of women and gender roles differ sharply from those in North America. Popularity of learning Spanish, trade agreements such as NAFTA, increasing political stability in Central and South America, and continued growth in the number of programs and students who seek study abroad experiences in that part of the world. 
In this paper I will describe and focus on two ways in which being a woman affected students' study abroad experiences in Costa Rica: (1) piropos, or unsolicited gender-oriented comments, and (2) women's friendships, their absence with women of the host culture, and the importance of friendships with other North American women. At least two other facets of the gender-study abroad relationship warrant attention but will not be dealt with here: gender and classroom experiences, and the different experiences of male and female students. First I briefly describe the University of Costa Rica, the status of women in Costa Rica, and the method employed in this study.

The University of Costa Rica and U.S. Study Abroad Programs

The University of Costa Rica, or La U as it is affectionately called, is the largest public university in Costa Rica, enrolling upwards of thirty thousand students in thirteen colleges and the Escuela de Estudios Generales. Four regional campuses are also located strategically in the country. The main campus is a large, nicely landscaped site located in San Pedro Montes de Oca, a suburb four kilometers east of downtown San Jose, the capital city. The campus is surrounded by inexpensive student eating places and bookstores. By Latin American standards the university is quite modern. The use of computers is widespread on campus, and the university is a Central American hub for the Internet. In addition to the main faculties, there are numerous research centers and institutes, many of which receive international funding. The university grants the bachelor's, licentiate (five-year degree), master's, and a few Ph.D. degrees. Because of unavailability of doctoral degrees within the country, the university sends many of its faculty abroad (to Europe, Latin America, and Canada, as well as the United States) to earn advanced degrees. In fact, one benefit the University of Costa Rica (UCR) gains from receiving U.S. students in study abroad programs is the ability to send faculty to the U.S. university for a reduced fee.

UCR has numerous agreements with many U.S. (and other foreign) universities for study programs of varying types. At least nine major U.S. universities have convenios with UCR, which allow U.S. students to spend from one to three semesters studying at the university. ${ }^{1}$ The largest of these programs, the longest continuously existing study abroad program in the Americas, has between forty and fifty students studying at UCR during any one semester. In this article, I call this large 
program GRANDE. Another program enrolls eighteen students, several programs enroll between five and ten students each semester, and one state university system's program enrolls approximately thirty students annually for one full academic year. Students in the majority of these programs take regular courses offered by UCR. Although some take one or two classes in English, the large majority of students take all of their classes in Spanish with Costa Rican students. Two medium-sized programs bring students to UCR but provide special classes for themsome Spanish classes and other subjects taught in English by UCR faculty. The two largest programs and one of the smaller programs have month long orientation sessions before the academic term begins. The two large programs employ on-site, full-time staff to work with students. The remaining programs employ UCR faculty members to work with students for a few hours a week or rely on the Office of International Affairs to serve students.

A basic minimum of two years of college Spanish is required for admission to the programs discussed above, with the exception of the two universities that have specific classes for their students. UCR has no control over admissions into these programs. Although there was some talk of requiring a Spanish proficiency test for admission, no such test had been implemented at the time this study was conducted. The GRANDE program is very competitive and accepts students from universities and colleges across the country. Participating students generally have very high grade point averages. The grade point averages of students in the other programs is not known. Although some of the students were Spanish majors, the majority carried double majors with Spanish as a second major or a minor field. Approximately 160 U.S. students were studying at UCR through one of the ten programs during the spring of 1993 .

In the spring of 1993, oversight of student programs was in the process of being centralized under the Office of International Affairs. The office had much direct contact with individual students, especially with students in the programs that did not have full-time staff. However, it had no control over the content or nature of the North American universities' programs.

There are no student dormitories at UCR because Costa Rican students customarily live at home with their families or with relatives. Consequently, most programs require students to live with host 
families for at least one month, and, depending on the student and the program, most live with a family for at least one semester. Study abroad programs see the family as an instrumental part of the cultural learning experience of the students as well as the main "teacher" of Spanish.

\section{The Status of Women in Costa Rica}

Costa Rican women enjoy a favorable position in society compared with that of many of their Latin American counterparts. In 1991 women comprised 49.5 percent of the total population of approximately 3.1 million people (Market Data, 1991-1992). Two factors that work in favor of women are a low birthrate and a relatively high level of education. Between 1960 and 1988 the percentage of women in the workforce increased from 17 percent to 28 percent (excluding domestic labor) (Garcia and Gomariz, 1989). It is in the area of education that Costa Rica stands apart from its neighbors. Only 6.9 percent of the female population was classified as illiterate in 1984. Furthermore, women comprise 50 percent or more of the students at every level of education in the country except that of higher education. But here women's participation lags behind that of men by only 1 percentage point or less (Garcia and Gomariz, 1989). In 1990, 37 percent of the faculty at the University of Costa Rica were women (Universidad de Costa Rica 1992), and UCR has an active gender studies program. In 1993 (during the sojourn of the students interviewed for this study), UCR hosted the Fifth International Interdisciplinary Congress on Women, which brought more than fifteen hundred women from all parts of the world to Costa Rica. A virtual alphabet soup of women's organizations exists in the country; and Margarita Penon, former Primera Dama of the country and credible precandidate in the 1993 presidential elections, worked openly for women's rights while first lady. All of this is not to say that Costa Rican women do not face obstacles; they clearly do. Many vestiges of machismo and gender inequality exist; however, compared with most other Central and South American countries, the level of machismo is lower and participation of women in professional roles higher in Costa Rica.

\section{Method}

Several sources of data were used in carrying out the project. First, formal interviews were conducted with students in the GRANDE 
program. A colleague and I approached the students in their orientation class and asked them to volunteer for individual interviews lasting approximately one hour. We interviewed twenty-one of the forty-one students; I personally interviewed thirteen students, and my colleague interviewed eight. Of the forty-one total students, eleven, or 27 percent, were men. Men (three) were underrepresented in our interview group. We also conducted small group interviews with students from several of the other programs, bringing the total of students interviewed to about fifty. We asked them open-ended questions about their experiences in the country, their goals for the experience, what surprised them, what they liked and what they didn't like, what advice they would give to other college students who were considering studying in Costa Rica, their definition of culture, and how they went about learning about the culture. With one exception, these groups tended to be dominated by women. (See also Tierney, 1994).

In late May, before I left the country, approximately four and onehalf months into the students' sojourn and one and one-half months before the end of their experience, I located and re-interviewed ten of the thirteen GRANDE students. The purpose of the second interview was to see how things had changed in the almost three intervening months. In addition I had many informal conversations with the interviewed students and other students in the GRANDE and other programs as I encountered them on campus or waiting by the program office. Interviews were not taped, but copious notes were taken.

A questionnaire administered by a second colleague to all North American students studying at UCR through one of the twelve programs in the spring of 1993 (Stage, 1994) served as a third source of data. A fourth, and important, source of information was the end-ofsemester yearbook published by GRANDE students in which they write very candidly, and often humorously, about their experiences in Costa Rica. I examined the yearbooks from the current and two previous semesters. They proved to be a very important source of information about experiences of previous groups, suggesting that the experiences of women in this study were not unique to one particular group of students. Student experiences were very similar across programs.

Several limitations of this study must be mentioned. First, we interviewed students who were, according to the research, somewhat different from their stay-at-home counterparts (Carlson et al., 1990). 
Because the Carlson study did not include students who study in Latin America, we do not know if there are yet additional differences between students who choose Third World study abroad experiences and those who go to Europe. Second, the students who chose to talk to us might have been very different from those who did not; therefore, we cannot generalize our findings to all study abroad students in Costa Rica. It is also possible that this particular group of students was different in some way from previous or subsequent groups to study in Costa Rica. What we do know is that the experiences reported by the students interviewed were very real to them.

My own personal encounter with the host culture must be taken into account. I was anything but a disinterested, detached investigator. In many instances I was observing, thinking, and experiencing the same things as the students. My experience with respect to gender, however, was different from that of the students, enabling me to be somewhat detached in my analysis.

The experiences as related by the students are divided in two sections: (1) piropos and their effects on women students, and (2) friendships. Tentative interpretations are proposed, followed by recommendations for study abroad programs.

\section{Piropos}

A Piropo: iay, que curvas y yo sin frenos! Ay, what curves and me with no brakes!

When we asked what general advice students would give to college friends considering going to Costa Rica to study, the following comment was typical: "If blond, dye your hair black." They offered this advice in response to the daily, what they perceived to be almost incessant, harassment they received from Costa Rican men. The harassment was mostly verbal-the famous piropo. In one view piropos are harmless flattering comments-expressions of appreciation of female beauty. Latin women are expected to appreciate them and take them as compliments. "For some they are a show of gallantry, a compliment from men toward the qualities of a woman; for others the piropo is also the opportunity to express a thought that isn't always directed toward beauty. The scene is familiar. A woman with certain characteristics or elegance draws comments, looks or gestures on the part of men who see her pass," reports Silvia Cabezas B., a reporter for La Nacion, Costa 
Rica's leading newspaper (in GRANDE yearbook, spring 1992, p. 18; translation mine.) She quotes a male Costa Rican author who says, "The piropo is very frequent in Costa Rica. A sharply dressed or attractive woman on the street knows that she will receive piropos" (translation mine). According to the sociologist Francisco Escobar, piropos have two functions: one is to send a very positive, flattering message and the second is to humiliate women publicly in order to demonstrate masculine superiority (Escobar in Cabezas B. in GRANDE yearbook, spring 1992). Cabezas notes that since the mid-1970s piropos have tended to be less complimentary and the piropoers from lower classes.

The women in this study knew they would receive piropos, which, they had been told, were harmless. However, as one woman said, she did not realize "that they'd \{piropos\} be so obvious." Because they were so frequent, so obvious, and so foreign to their way of thinking, students were unable to ignore them. For many women interviewed in this study piropos served as constant and powerful reminders not only of their sex but also of their status as outsiders in a foreign culture.

Students agreed there were good and bad piropos, a fact that was confirmed by their male Ticos ${ }^{2}$ friends. In their mild form, piropos take the form of sayings like Machita más bonita (Most beautiful young woman); Hola angel (Hello angel); Te beso (I'll kiss you); Ojos azules (Blue eyes); Macha, machita (Baby); En que puedo servirle, reina? (How can I help you, darling?); Guapa (Beautiful); and Muñeca (Doll). Although the sayings may seem rather harmless, even humorous, the North American 3 women students typically failed to see the humor in them.

If these seemingly harmless statements were what Ticos mean by "pretty" piropos, the "ugly" ones were equally simple and prevalent. "We get all the rude piropos," said one student. "We don't get the nice piropos. It's the tone of voice." The North American students agreed that fortunately they did not understand some of the really bad piropos, but there were two really offensive ones that they understood perfectly well. These were rica which means "rich" and is intended in a very sexual sense, and hissing or the ever-present "psssst!" "Hissing makes me most mad," said one woman. Another described why she didn't like hissing. "Hissing is bad because that is what they do to dogs." "The worst is hissing because supposedly it is really sexual," added another. 
Some students described even more explicitly sexual piropos. One young woman said, "Sometimes it is the looks more than the verbal. Sometimes I just want to put a blanket over my body, especially when I pass a group of men. 'Vamos a hacer el amor' (Let's make love) is one of the bad ones I have experienced. Sometimes I don't understand them and it is just as well." Several others agreed that the looking bothered them. "Guys staring and whispering and the laugh they have when they are in a group. When I wear a dress, it is worse," said one. Another said, "It is not just the act of saying piropos, it makes me tense to walk by men. I feel very vulnerable." One woman described being in a bookstore when a man "dressed in a suit with his two little boys started sticking his tongue out at me. No wonder all the men here do it. Little boys learn at a very early age. And he wasn't even a worker type. This is much worse than Chile." Another student reported an experience at the beach during orientation in which a man left his family to come and stare at a few of them. Yet another woman said that she had experienced a situation in which a man with his arm around a woman was mouthing sexy things to her. One of the joggers in the group said, "When I am running, the way they $\{\mathrm{men}\}$ look and hiss...it will take some time to get used to."

Two students reported more direct, physical forms of harassment. However, physical harassment of women, such as the "butt grabbing" described by one of these women and chasing experienced by the other, is not common in Costa Rica.

The students all agreed that the situation was much worse away from the campus. It was not college students who practiced piropoing. (Other forms of harassment do occur on campus.) Although some women had negative encounters with professional men, it was most often the "man on the street" who hissed and yelled piropos. Students disagreed whether their neighborhood was a safe haven from verbal harassment. Most felt comfortable in their neighborhoods, but one student said: "In the neighborhood I can't walk out the door two blocks to the bus stop without men yelling. There are two men in the local store in my neighborhood who tell the others not to do it." When I asked this woman what the men said to her, she said that "one day they were talking about my boobs." Many students lived close enough to campus to walk and often found themselves bombarded by unpleasant piropos. 
"Women Like Piropos," and Other Explanations

Women students developed a number of their own theories to explain why men engaged in piropoing. Some understood piropos as just part of the culture and recognized that Ticas endure much harassment, too. However, most believed that Ticas like being piropoed; that piropos were necessary to their self-esteem. Most agreed that North Americans frequently received ugly piropos with anti-North American overtones. When students engaged other Ticos/as in conversation about piropos, they usually talked to men (for reasons that will become more obvious); but the students reported that even many Ticas said they liked piropos and considered them flattering. They frequently heard the explanation that piropos used to be considered a beautiful part of courtship-like poetry, but now they are ugly and disgusting. Most of the women students rejected the idea that piropos are harmless, beautiful, flattering (as did many of my professional Costa Rican women friends), and even that they are a part of the culture. They least of all accepted the fact that women might like them: "I don't understand why women like them." "I can't accept that it is part of culture and not machismo." "Women here see it as a compliment, but we don't see it that way at all." One woman was astonished when a professor, who had done a study on piropos, concluded that women make themselves up because they want to receive piropos (emphasis mine).

Another popular explanation: "Ticos have stereotypes about North American women that they are all loose. Ticas \{women $\}$ think that too," said one student. Another said, "Costa Rican men think that all gringas are easy. They just want one thing. "For some, piropos were an extension of a general view of women in Costa Rican society. They talked at great length about things their families told them, such as "women shouldn't walk around barefoot in the house because it will damage their ovaries." One woman's "father" criticized her for not having long fingernails, that is, for not being more feminine. He observed that all the women in the United States were losing their femininity. Several talked about the role of their "mothers" in the family and, in the words of one student, the "get-me-a-sandwich" attitude of some of the "fathers."

My Walkman, My Best Friend 
Piropos were clearly upsetting to these women; therefore, it is important to note how these women responded to piropos and what effect they had on their study abroad experience. One student noted, "I don't know if they piropos really happen so often or if I just imagine they are going to happen." By a certain point the women students expected that piropos were going to happen, and they reacted accordingly regardless of whether they received piropos or not.

Most acknowledged the harmless nature of piropos and admitted that they should have ignored them. Almost all said that piropos bothered them more when they had had a stressful day. In fact, their reactions to piropos may have been due to their lack of adjustment to other aspects of the culture. And as our interviews with students indicated, they had plenty of stressful days induced by the academic system (see Tierney, 1994). Part of their frustration resulted from not knowing how to respond effectively to piropoers. Some said that they wanted to "give the piropoer the finger" or that in the States they would feel more comfortable "flipping someone off." Some wanted to scream back and some tried that. A couple of women talked about actually using their umbrellas as weapons in defense against would-be verbal attackers. One woman adopted an offensive strategy. She talked to would be piropoers before they had a chance to harass her. One woman said it made her feel much better just to think about what she would say to the men if she felt she could say something. This response, in particular, illustrates how women are silenced by cultural norms and language differences.

Their attempts to talk to Ticos/as about piropos were not very satisfactory. One woman reported her attempts to discuss the issue. "Sometimes I want to engage them in a conversation about how it makes me feel," she said. "I got in a conversation with a fellow named Luis on the bus. He started talking about astrological signs, etc., and about how all of the women he had had and about how he had made a woman's eyes spin seven times that day. I told him that it offended me when men treated women like an object. He then said to me, 'What do you want to talk about then?' as if there were absolutely nothing else to talk about." Although she viewed piropos as harassment, one student said that she did not think it was her job-or that of any North Americanto change Costa Rican women's attitudes. This student also noted that many Ticas did not like piropos either. The most disturbing response: 
wear a Walkman to block out piropos. Several students referred to their Walkman as "my best friend." This response is particularly troubling because, in addition to blocking out piropos, the Walkman allowed the wearer to shut out other aspects of culture as well.

The seemingly harmless words of which most piropos consist shaped the behavior of students in other ways. The most obvious effects were a modification in where women students walked, feelings of mistrust of men, feelings of alienation from Ticas and Ticos their own age, and inability to have male friends. This reveals a contradiction, because the women reported that it was generally easier to have male than female friends and many dated Ticos or had boyfriends. One older student summed up nicely the sentiments of many of the women:

I thought I wouldn't have as many piropos because of my age, but any gringa is a good target. I talked to my conversation partner here and she said that everyone likes them here. It is hard for us to deal with that. The program assistant coordinator suggested slapping the men or spraying them with Mace. I feel sad. I don't feel that I can be open ... I just don't look at men at all. I like to talk to older people, and one day I said "hi" to an older man and even he came back with a piropo.

Another said, "I just wish that I could walk down the street. I always think when I walk by a man, and I don't want to pass them on the street. And I don't want to walk by them in a restaurant to pay for a meal, for example. For a while I felt like I didn't have a right to walk down the street. There is no reason I should feel badly for walking down the street in the middle of the day. You have to either ignore it or let it change your life... I feel intimidated by the men here." Yet another said, "You are always aware that you are a woman." Being aware that the men were not going to do anything dangerous didn't make most of the women feel any better. "I feel very vulnerable," said one. "Just to walk by men makes me feel tense."

The women did not change their mode of dress in response to piropos. The students from one program talked at great length about piropos in the context of "presentation" in general. By this they meant that Ticas always looked nice. They never wore "sweats" to class. "At 
home, no one walks around in a bathrobe. Students are always brushing teeth and putting on makeup." "They \{Ticas\} are always redoing themselves after lunch," explained one woman in one of our group interviews. Another woman in this group told about feeling selfconscious one Saturday when she wore shorts to take a test. "Everyone else was so dressed up," she said. At least this woman recognized she was out of place.

This particular group of students admitted facing a dilemma of adjustment. They were going to spend an entire year in Costa Rica. Their main goal was to integrate as much as possible into the host culture, but when some aspects of the host culture values, such as mode of dress, clashed too severely with their culture and sense of self, the students questioned not only whether they could ever adjust but whether they wanted to. Although one might not expect a North American student to dress like the Ticas dressed, there was a greater gap between the way North American women and Ticas dressed and the way in which the males from the two cultures dressed. With the exception of the group of students mentioned above, none of the other North American women even mentioned the idea of modifying dress, for example, by not wearing shorts to class. And only one said that she would no longer wear shorts downtown. Several others said that they wore baggy clothing to avoid looking sexy. Although they didn't like sticking out, they did so. Both male and female North American students were easily identifiable. Changing mode of dress would not have made them necessarily less identifiable, but it would have served as notice that they were at least aware of cultural norms.

"No Females in the Group Have Tica Friends"

Although it sounds terribly stereotypical, most of my female gring a companions have come to the conclusion that it is also easier for the males here to make friends. I wish it were not the case. (GRANDE yearbook, spring 1992, p. 6o)

Two dimensions of friendship were important to students interviewed for this study. First was having friends in the host culturemales and females-and success or failure in this aspect of their lives played a very important part in their experience. Second, North 
American friends, particularly women from their own or other piropos, were more important than any of the students anticipated-or wantedwhen they began their experience in Costa Rica.

For most students increased language proficiency was the main reason for choosing to study in Costa Rica. A second objective was learning the culture. Making Tico/a friends was identified by these students as an important way to accomplish these goals. For the women, having female friends was particularly important. However, as becoming fluent in Spanish was more difficult than students anticipated, so was making friends. When asked if they had Tico/a friends, many echoed the sentiments of the one woman who said, "Not as many as I'd like. Just a couple in classes." This student admitted that she had not made much of an effort to get to know Ticos/as. In some cases families compensated for the lack of Tico/a friends, and frequently the family served as the contact for the friends students did have. Although they frequently developed very close relationships with families, even calling the various members "mother," "brother," and "sister," and appreciated meeting relatives and neighbors through the family, these friends were not enough. One woman admitted with some frustration, "I have resigned myself" to the fact that the family would be the main source of friends throughout the sojourn in Costa Rica.

Tico and Tica friends were a logical way for North Americans to have contact with people their own age, avoid loneliness, and, most important, become part of or at least learn about the culture. In this strange culture, however, they were at somewhat of a loss as to how to make friends. One woman described her frustration: "During the first few weeks I was desperate to make friends. We were all worried about it. We all asked, 'How do you do it?"' Some women went so far as to say that it was easier for North American male students to make friends.

The university friends they did make were in-class friends. One student observed, "I do have friends in classes; but when I leave the class, I leave the friends." While most students we talked with admitted that Ticos/as were friendly once they got to know the North Americans individually, they reported feeling some anti-North American sentiment, and even hostility. One student described a class in which all of the North Americans sat on one side of the room and all of the Ticos/as sat on the other. Most North American students preferred to take courses with few other North Rican boyfriends or girlfriends or 
dating Ticos or Ticas. One student said she was glad to have a boyfriend. Not only did he provide an entry into the culture, but he protected her from the constant harassment women typically faced.

Perhaps surprisingly, women students reported it more difficult to make female than male friends. Four months into their stay, most students shared to some extent the frustration of the woman who said, "Socially, despite my good intentions and (sometimes naive) openness, my rejection by other female students has been complete." The women in one program that has its own courses were particularly strong in their sentiments. They said things like "The attitude of women here toward North American women is unfriendly. Even if you try to smile they respond with dirty looks." One woman in this same group assured us that "no females in this group have Tica friends." The North American women did admit that some Costa Rican women were friendly in class. One woman in the GRANDE program said that as the only North American in one of her classes, she had made friends with a Costa Rican woman and that they had even gone out for a glass of wine together. Another student played volleyball on a team of Costa Rican women. She said that the students had invited her to do things, but that she had not done much with them off the court. In view of these students' experiences with men in Costa Rican culture, the fact that it was easier for them to be friends with men is just one puzzling aspect of these students' perceptions of their experiences.

Conversation partners were a good source of friends for the students who volunteered (dared?) to have one. Many Costa Ricans want to perfect their English, and English majors seek out North American students as language partners. Generally these partnerships allow students to practice the foreign language and to make friends as well. One student wrote in the GRANDE yearbook about her three language partners whom she would meet each week to talk about life in Costa Rica or in the United States: "In both cases Ishe met with one individually and with the other two together\} I have felt a sincere cordiality, and I will never forget the spirit of sharing" (translation mine). Unfortunately, relatively few students took advantage of this opportunity during the semester in which this study was conducted. Some students volunteered to work with organizations outside of the university, which they described as a beneficial experience. 


\section{"Our Lives Are So Different"}

The students had theories about why it was so hard to make female friends. Some of the explanations revolved around competition. For example, a woman from one of the larger programs said, "It is much more difficult to meet women. I don't know if they are jealous or not since I don't have any close Tica friends." This same student went on to say that Costa Ricans have stereotypes that North American women are loose, that is, that they are willing to engage in sexual relations with strangers. Another student observed, "Women are not interested in being our friends. They only want to meet gringo guys." For Costa Rican men, "A gringa girlfriend is a trophy and the Ticas understand this," added another woman. North American women believed that "especially the women have preconceived ideas of how American women are. Once they get to know you through class projects, etc., they become friendlier and warm up."

Another theory centered on the differences in the lives of Ticas and North American women. One woman said that she hadn't discussed piropos with any Ticas because "life is so different. Women are always kept in the house. Boyfriends can only come in when the father is home. They watch TV and paint their nails." She explained that this "sometimes engendered resentment" because the North Americans had more freedom than the Tica daughters. Another observed that "the guys \{Ticos\} are more social." A woman student from the GRANDE program said that "it was easier to have male friends than female because it is hard to get into their \{the women's\} conversations." And yet another student said that it was difficult to form friendships because "our lives are so different. It is hard to find things to talk about." One student noted that "it is hard to have friends, but it is not their fault. Ticas in class are friendly but they don't do anything outside of class." This included travel. "We like to travel and they don't," said one student.

Still another explanation centered on the very nature of social relations. One woman said, "I feel like I am in high school all over again. We've seen a different lifestyle. People live with families. It's hard to make friends because they have lived in the same place with the same people all of their lives." Another student commented on the difficulty of "breaking into the cliques." She said, "It is easier to make friends with guys than with women. It is harder to break into cliques and they all seem to have them from high school. They are nice in class but they 
never seem to go out. Guys seem a lot more interested." These students felt like outsiders and seemed to have little idea about how to break into friendship circles. Perhaps an even more important insight, shared by a number of gringas, was summed up by one student: "We are used to living in dorms. At home, college is our life. Here it is different. The university is only part of life." For Costa Rican students, college, and the friends made there, compete with family and work much as it does for commuter students in the United States.

Many reported being surprised that as a guest in a foreign country their hosts and hostesses did not bend over backward to welcome and befriend them. When I asked the conversation partner of a GRANDE student about why it was hard for the North American women to meet and make Costa Rican women friends, she responded without hesitation: "Some groups are really friendly and some are not," she said. English majors really like to have North American conversation partners to share with and to practice. They particularly want to hear the accent and to learn about U.S. culture. But some students are standoffish. They act like they don't want to talk to us." This observation suggests that the real explanation for the perceived inability to make friends in the host culture is a two-way street. When making friends in the host culture was difficult for North American students at UCR, they had many other gringos/as to turn to for friendship.

The Gringo Tree

"It was hard to make Tico friends-most of us never really didand we needed each other to truly enjoy our time here." (GRANDE yearbook, fall 1992, p. 12)

When trying to arrange second interviews with students, I asked the assistant in the GRANDE office where I might meet the students, since by this time the arrival of the rainy season was imminent. She responded immediately: "Under the Gringo Tree." 4 The plaza in front of the main library was a favorite gathering place for all students; but gringos and gringas could be found gathered under one particular tree. When the rain arrived in full force, the gringos/as merely moved across the street to Monpik, a local ice cream store. This tree became 
important as a symbol of both why it was difficult for them to make friends and what happened when they did not.

In the students' own words, spending as little time as possible with other North American students was one of their intended strategies for immersing themselves in the culture. During orientation they reported anxiously awaiting the beginning of the regular school term so that they could escape from the mob of North American students. However, other North Americans in general and women in particular became very important for female students. What happened to thwart their original objective?

"The other North Americans who choose to study abroad are the kind of people you like to know," offered a male student. Other North American friends also helped students to learn about the culture. They experienced things together when traveling, studying, and living with families, and their North American friends helped them make sense of those experiences. In addition, other North Americans had the shorthand and common language that made sharing with their North American friends more satisfying. As one of the most Spanish-fluent students said, "I have Tico friends, but my good friends are other North American students. They are experiencing the same thing I am. They know what it is like to miss boyfriends and chocolate chip cookies."

North American women students became particularly important to each other. Women friends helped them to maintain a sense of what it meant to be a woman in the United States. When asked if piropos were still troublesome to her, one student responded that she had stopped thinking about gender issues because it had become too depressing for her. She went on to tell me that women friends from the United States had been very important to her because, "when people start telling me that I am a fanatic \{about women's rights, etc.\} I lose confidence and contact with reality. Women friends set you straight.... When I question myself about cultural differences I go to my roommate from college \{also a student in the GRANDE program\}." One woman summed up nicely the role of women friends:

I've always been somewhat of a tomboy; most of my best friends have been gays. I've heard many of you express the same. I've tended to be "anti-girl" because hair spray, makeup, and giggles without concrete conversations don't constitute a 
friendship to me. But in this group, I've met some intelligent, strong-willed women who impress me as wonderful people. I've gained new faith in feminism. (GRANDE yearbook, fall 1992, p. 11)

Others also said that they had become more feminist as a result of the study abroad experience.

\section{Discussion and Recommendations}

Students routinely report that they enjoyed their experience in Costa Rica, and it is important to keep in mind that the overall experience is a good one for most students who go there. However, this research done on-site, during the sojourn, suggests that the experience can be a very lonely, alienating one for the first four months or so, especially for women, made so in part by piropos and difficulties making friends in the host culture. By the fourth month in the country the students interviewed for this study were still struggling with these issues. While most students adapt to the culture eventually, the vast majority of these students had planned to spend only six months in the country, shortening the time they have to adjust and to benefit fully from the study abroad experience. Because the majority of students spend only one semester in Costa Rica and the majority of these students are women, the important question is this: What can programs do to structure critical cross-cultural learning experiences out of the cultural differences?

Attempts to confront the problems that women students face must be based first and foremost on an acknowledgment that the problems exist. The most common advice these students received was that piropos are harmless and that they should ignore them. The advice is entirely understandable. Generally, piropos are harmless, and had I not interviewed these students, I would not have identified piropos as a problem in Costa Rica because for me they were not. However, by merely telling students to ignore piropos, we not only deny their experiences and the importance they have but also shut off consideration of constructive ways of dealing with them. In addition, we contribute to the already powerful forces to silence women. Study abroad programs face a dilemma: on one hand, to emphasize gender 
issues might scare some students away from study abroad; on the other hand, to ignore or play down the issues may inhibit critical learning from taking place. The objective should be not to change the host culture but to convert problematic situations into critical learning experiences for students.

As reported earlier, students developed theories to explain both piropos and their difficulties making friends in the host culture. However, putting the findings in a broader context, we can look to several factors to explain why women have such a difficult time with both issues. The findings and conclusions of this study should be viewed as they are intended-as tentative conclusions from an exploratory study. However, what the findings suggest is that culture shock or the process of adaptation to new cultures is different for men and women, made so by the interaction of cultural and socialization factors of both sending and receiving countries. These gender differences must be taken into consideration.

Much of what the women were experience can be viewed within the framework of "culture shock," a familiar topic in study abroad programs. Culture shock is typically described as a process of moving through a series of stages from contact with the host culture through a period of alienation/adjustment to biculturalism, or some variation thereof, in which the host country is seen as having positive and negative aspects and the sojourner learns to accept and act within the norms of the host country (GRANDE Study Abroad Handbook, 1992; Gullahorn and Gullahorn, 1963; Hogan, 1983; Oberg, 1958). The students interviewed for this study were probably somewhere in the middle of the adjustment/alienation stage during which, finding lack of consensus between their own and the hosts' expectations of appropriate behavior, sojourners either begin to understand the foreign culture and to enjoy themselves or remain extremely dissatisfied with the host culture. Gullahorn and Gullahorn (1963) argued that similarity of task related values and goals and ability to reduce dissonance are particularly important for generation of positive sentiments about the host culture.

These women students confronted several dissonance-producing situations, some of which seem unique to women and others common to both sexes. They had only very general ideas and values about university study, about people of their own age, and about appropriate 
and inappropriate behavior with respect to women-what constitutes harassment and what does not. In fact, almost all of the students we interviewed said that they knew very little about Costa Rica before going there. They admitted having tourist information but not knowledge of what language educators refer to as "hearthstone culture." Inevitably their ideas clashed with reality.

The North American women students' ideas about women and harassment and about forming friendships differed sharply from what they encountered in the host culture. Although many Ticas do not like piropos, many others do not find them offensive. In the context of a very verbal culture in which terms such as negrita (darkie) and gordita (fatso) are regularly used as terms of description, even affection, piropos are accepted as normal if not flattering. Most Ticas do not consider them a form of harassment, although their attitudes are slowly changing. North American women students knew little of the role of piropos in the culture, however, and they could not imagine why any woman of their own age could possibly like piropos. In terms of their own value systems, piropos were a form of harassment. Even when Costa Ricans described piropos as a form of flattery, the explanation was rejected. In short, they wanted their hosts to interpret piropos as they would in the United States. These experiences reinforce the arguments of JoAnn deA. Wallace, who says, "Young women who have been intellectually nurtured with the 'personal is political' model may find it very difficult to adjust to a culture in which feminist activism has not yet been defined or perceived as necessary" (p. 5).

Making friends, particularly women friends, was a second dissonance producing situation. Developing friendship relationships in a foreign culture is difficult (Gullahorn and Gullahorn 1963), and as the students themselves suggested, they did not really know how to do so. Again, the women had grown up in a society in which women's friendships were important to them. However, in their new cultural context they found that lack of common interests, different social structure, cultural attitudes about dating (for example, Ticos want to date only gringas), and participation in different types of leisure activities inhibited friendships. Making friends was more difficult because the North Americans were entering a collegiate environment in which many Tico students had been friends since childhood. In contrast, when most of them had entered their North American 
universities, they had encountered others who had left home and friends, and who had to make new friends. The process of making friends was also complicated by the fact that many students were only functionally fluent in Spanish when they arrived in Costa Rica. In addition, some believed their hosts should make the effort to befriend them as guests in the country. Cultural norms about the role of women in society seemed to make the development of friendships more difficult for women than for men, and yet students had very little understanding that making friends would be so difficult or that they might have to adjust their ideas in order to befriend Costa Ricans.

As the Gullahorns (1963) noted, when sojourners find more dissimilarity than expected, they attempt to reduce the dissonance in some way. This may include reverting to fellow North Americans or, in extreme cases, leaving the country. The Gringo Tree was symbolic of one such response when they found making friends in the host culture difficult. At one point gringo/a-Tico/a relations were constructed as a "contest" between Costa Ricans and gringos as North Americans sought support for a pair of gringos in the finals of a salsa (dance) competition. Signs on the GRANDE office door asked North Americans to turn out in a show of "Gringo Power."

It must be noted that it was difficult for North American students to avoid each other because there were so many of them. One might even argue that students enjoyed their experience in Costa Rica primarily because of other North American students. As Tierney (1994) points out, even though the gringos/as hung out together they often did Costa Rican things, such as going roller skating-something the students said they would never do at home.

A third dissonance-producing factor was that Costa Rica IS a confusing country with respect to culture shock. At first it appears very North American. When we asked students what initially surprised them the most about Costa Rica, we heard the following: "I'm waiting to be surprised" or "I feel like I am in a Miami barrio." Evidence of North American culture is everywhere. One can eat at Pizza Hut, buy Chicago Bull's T-shirts, hear English spoken on the street, watch CNN and network TV from Denver, and even live in a neighborhood with other North Americans. One can be easily fooled into expecting North American norms and behaviors. Some of the difficulties that women students had with piropos may have rested with this characteristic of 
Costa Rica. When it turned out that culturally things were really different, students were not prepared to deal with the differences.

Fourth, college life in Costa Rica is different from that in the United States. The students frequently noted that in the States college was their whole life, whereas in Costa Rica it was only part of their life. In Costa Rica women students are much more exposed to the vagaries of daily city life and are not sheltered by a comforting college campus or college town. Even when harassed by a group of construction workers, for example, in the United States, women have language skills and knowledge to respond to their harassers. In Costa Rica, because of language and cultural differences, they do not have such response patterns readily available to them. Neither do they feel free to respond.

Fifth, the North American students with whom I talked had, by their own admission, set their expectations too high. Their goals of becoming fluent in Spanish and integrating into the culture had been greatly modified by the time of the second interviews. They realized that they were not going to have dozens of close Costa Rican friends, nor would they be as fluent in the language as they initially thought.

Unfortunately, to this list one must add a "blame-the-victim" explanation for piropos. The students were in the tropics. They expected it to be hot and they frequently dressed accordingly (shorts), even though it is actually quite cool in San Jose. In addition to standing out because of light hair and light-colored eyes, they stood out because of the clothes they wore, thus, perhaps inviting piropos. Costa Ricans seldom wear shorts to class or in the city of San Jose, but it never seemed to occur to most North American students that they should modify their dress to conform to cultural norms. Even second-semester students continued to wear clothing typical of North American college students. In this one aspect, North American students never seemed to adopt the norms of the host culture. They allowed their own conceptions of identity and individual rights to persist. The director of one study abroad program not officially affiliated with UCR, herself a gringa, tells students straight out that they can dress as they wish, but if they wish to minimize unwanted attention, they should wear loose clothing that covers their bodies well. She also attempts to downplay the importance of piropos by contrasting them with date rape in the United States. While recognizing both positive and negative aspects of the host culture, the students in this study had not reached a stage in 
which they would sacrifice their own right to individuality for cultural norms with respect to dress. Nor is it clear that they understood that acting within the norms of the host culture was something they should strive to do, or that there would be consequences if they did not.

\section{Recommendations}

Although it is true that most students enjoyed their time in Costa Rica studying in another language, living with families, and traveling, they may not have developed the depth of cultural understanding-at least during their first six months-required to reach the desired goals of study abroad. For women the problem of piropos and perceived inability to make Costa Rican women friends both reinforced their status as outsiders and made their entry into the host culture problematic. It is my premise that programs can take several relatively simple steps to help students enter into the host culture more fully and to improve cross-cultural learning. Here I will direct my comments specifically to activities targeted toward addressing the problems experienced by the women in this study. (See Tierney, 1994, for a more in-depth treatment of curricular recommendations.) These recommendations assume a pre-travel orientation such as described by JoAnn deA. Wallace. It goes without saying that students should be encouraged to stay for one entire year. Six months is very little time to work through the stages of culture shock to arrive at a point at which one can truly begin to learn about the country and the culture.

1. Programs should create a forum for women students to discuss piropos and cross-cultural views of gender. It is insufficient to tell students that they will experience piropos and that they should ignore them. They cannot ignore them nor does warning them about piropos during orientation seem to do much good. It is when they hear piropos, and experience firsthand the feelings of alienation or being rejected by Costa Rican women, that a serious discussion of piropos and friendship norms becomes most relevant. Students need a serious academic forum, preferably led by trained persons from the host culture, with students from the host culture, in which to discuss these issues during the semester and not just at the beginning.

Several ways to accomplish this come to mind. One is to arrange with women's studies faculty members or interested women faculty to conduct orientation sessions on the topic of piropos and other gender- 
related issues. They could plan several sessions: one during the regular orientation before the academic term begins and additional sessions during the semester in which they could deal more specifically with the issues that arise as a result of piropos. As faculty members and as women from the host country, they could couch these discussions in terms of the role of women in the larger society. As role models they would dispel some of the stereotypes the North American women students seem to have about their, in this case, Costa Rican counterparts. A second possibility is to offer a cross-cultural course on gender. This course could be taught by women's studies faculty members or jointly by North American and host country faculty members and be open to students from both. It could be taught in Spanish or English or both. One study abroad program not directly connected with UCR offers a course on women's issues in Central America as one of several electives its students can take before they go off to do their internships. Whatever option is chosen, to be effective in enhancing cross-cultural learning it must involve both citizens from the host country and North Americans, preferably as teachers and as students.

2. Develop ways to help North American students connect with the host culture. One program encourages volunteer work, but it is not required of any program. Specifically, programs could do more to help students make friends in the host culture. In this respect programs that have alumni in the area have definite advantages. In the specific case of Costa Rica, it would seem relatively easy to arrange more involvement between alumni and North Americans early in the students' stay. Perhaps each North American student could have a "host" family in addition to the family with whom they live. Costa Rican students could be included in some of the orientation activities. As mentioned earlier, students of English and Teaching English as a Second Language are very eager to meet North American students and to form conversation partnerships, if not friendships. They provide a ready source of Costa Rican participants.

3. Families with teenage or college-age children should be given preference as housing options. One program requires its host families to have children living at home. If this is not possible because finding suitable families is a difficult task, families could be encouraged to introduce their students to friends and relatives. Families do much of 
this already. Personal experience suggests that students live with a wide variety of host families, and families themselves reported receiving little information or instructions as to what to do. Responsibility is placed on the family for providing much of the student's cultural and language education and yet little attention is given to this aspect of the program. More formal suggestions could be made to families about the role they should play in the student's education.

4. More research needs to be done on the gendered nature of study abroad. Qualitative research done during the sojourn is also desperately needed. Retrospective reflections may not catch important differences in study abroad experiences.

Although these four relatively simple recommendations will not change the reality of either piropos or friendship norms of the host culture, they will at least provide the basis for discussion, reflective thinking, and critical learning to take place. Study abroad programs cannot assume that just bringing a student to a-foreign university and taking care of procedural issues such as registration are enough to accomplish the intended goals of study abroad.

\section{Works Cited}

Burn, B., and Smuckler, R. 1990. A National Mandate for Education Abroad: Getting on with the Task. Washington, DC: National Association of Student Affairs.

Carlson, J.; Burn, B.; Useem, J.; and Yachimowicz, D. 1990. Study Abroad: The Experience of American Undergraduates. New York: Greenwood Press.

García, A. and Gomáriz, E. 1989. Mujer Centroamericanas: Tomo 1. Facultad Latinoamericana de Ciencias Sociales, Consejo Superior Universitario de Centroamérica, Universidad para la Paz.

GRANDE End-of-Semester Yearbook, spring 1992.

GRANDE End-of-Semester Yearbook, fall 1992.

GRANDE End-of-Semester Yearbook, spring 1993.

GRANDE Study Abroad Handbook.

Gullahorn, J.T., and Gullahorn, J.E. 1963. "An Extension of the UCurve Hypothesis.” Journal of Social Issues, 19 (3), 33-47.

Hogan, J. 1983. "Culture Shock and Reverse Culture Shock: Implications for Juniors Abroad and Seniors at Home." Paper presented at the annual meeting of the American College Personnel 
Association, Houston, TX. ERIC Documents Reproduction No. ED2332698.

Oberg, K. 1958. "Culture Shock: Adjustment to New Cultural Environments." Practical Anthropology, 7, 177-182.

Pickert, S. 1992. Preparing for a Global Community: Achieving an International Perspective in Higher Education. ASHE-ERIC Higher Education Report No. 2. Washington, DC: George Washington University, School of Human Development.

Stage, F. 1994. "Research Based Means for Improving International Exchange Programs." Paper presented at the annual meeting of the American Educational Research Association, New Orleans, April.

Tierny, W.G. 1994. "Multiculturalism and Studies Abroad." Paper presented at the annual meeting of the American Educational Research Association, New Orleans, April.

Universidad de Costa Rica. Oficina de Planificación Universitaria. Perfil del Funcionario Docente, 1992.

Wallace, J. deA. 1993. "Leveling the Playing Field." CIEE Update, 5 (May), 12.

\section{Notes}

${ }_{1}$ There are many more convenios between UCR and foreign universities for short-term and other types of programs. In this study we dealt only with the universities that regularly send students to study for at least one semester.

2 Tico and Tica are the shortened masculine and feminine versions of Costa Rican. They will be used throughout this article. The same linguistic pattern holds for the terms gringo (male North American) and gringa (female North American). The term is used merely as a descriptor and is not meant in a negative way.

3 The Spanish language has a word for people who come from the United States. We tend to use the term American, which technically includes people from Canada and Central and South America. I use the term North American in this paper even though it is far from a perfect choice.

4 The Gringo Tree was apparently a creation of this particular group. Program staff who went to UCR in October 1993 said that the group of students there at the time knew of no such tree. 